Journal of Research in Interprofessional

Practice and

Education

Vol. 6.2

2016
Journal of Research in Interprofessional Practice and Education (JRIPE)

Vol. 6.2

(C) 2016

Corresponding author: Maurianne Reade. Email: mreade@nosm.ca

\section{The Impact of Hidden Curriculum in Wilderness- Based Educational Events on Interprofessional Competencies: A Mixed-Methods Study}

\author{
Maurianne Reade, MD, CCFP(EM); Marion Maar, PhD; \\ Nicole Cardinal OCT, MA; Lisa Boesch, BA; Tara Rollins, RN, \\ \& Nicholas Jeeves, MD, CCFP \\ Northern Ontario School of Medicine \\ Sara Lacarte, MA \\ Laurentian University
}

\begin{abstract}
Background: The purpose of this study was to determine if interprofessional skills, attitudes, and behaviours could be learned during an austere medicine educational activity where interprofessionalism remained within the informal and hidden curriculum.

Methods and Findings: We used a mixed-methods approach to examine the potential acquisition of interprofessional competencies during wilderness medicine educational events. Thirty-four participants, over two events, completed interprofessional learner contracts, audio diary entries between patient scenarios, and the Interprofessional Collaborative Competency Attainment Survey (ICCAS) using a retrospective pre-test/post-test design. Audio diary entries showed the reflection that took place between scenarios during the orienteering portion of the event and the adjustments toward interprofessionalism that took place. Both the survey and audio diaries confirmed that participants perceived an improvement of their interprofessional competencies after the WildER Med event.

Conclusions: The outcomes confirm that interprofessional competencies can be developed during a learning event such as WildER Med, where the interprofessional curriculum is hidden. Austere medicine, which is at the base of this learning event, represents an opportunity for the further understanding and exploration of interprofessional education.

Keywords: Interprofessional education; Informal curriculum; Hidden curriculum; Austere medicine; Mixed methods
\end{abstract}

\section{Introduction}

Interprofessional Education (IPE) and Interprofessional Collaborative Practice (ICP) have become themes of increasing visibility and dominance in healthcare curricula. Interprofessional healthcare teams are one approach to address concerns over "adverse events, medical errors, compromises in patient safety, poor quality care, and links to preventable patient mortality," [1, p. 2-273] which are often linked to "poor communication and collaboration, and ineffective teamwork" [1, p. 2-273].

The Centre for the Advancement of Interprofessional Education (CAIPE) defines IPE as "occasions when two or more professions learn from and about each other to 
2

Hidden Curriculum in Wilderness-Based Education

Reade, Maar, Cardinal, Boesch, Lacarte, Rollins, \& Jeeves

Journal of Research in Interprofessional Practice and Education

Vol. 6.2

2016 improve collaboration and the quality of care"[2]. IPE provides a unique opportunity to share skills and knowledge among professions and promotes improved understanding, shared values, and respect for the roles of other healthcare professionals. IPE may not only be part of the formal curriculum, but may be part of the informal or hidden curriculum as well [3]. Course developers have been encouraged to consider each of these aspects to maximize the impact of educational interventions [4].

Ultimately, IPE should prepare health professionals for ICP. The World Health Organization describes ICP as occurring "when multiple health workers from different professional backgrounds provide comprehensive services by working with patients, their families, carers and communities to deliver the highest quality of care" $[5$, p. 13].

Austere medicine refers to the practice of medicine in resource-constrained environments and may include remote healthcare clinics, wilderness rescues, airambulances, disaster and mass casualty, or tactical operations [6]. Interpersonal skills, including communication, teamwork, humour, and leadership, are considered significant skills for all healthcare personnel working in austere medicine settings $[7,8]$. Austere medicine educational activities may facilitate the development of interprofessional competencies (IPC) $[9,10]$. Examining interprofessional teams within the high-stress environments of austere medicine have relevance to other areas of medicine particularly for more fluid teams where "personnel must tolerate rapid change and high levels of ambiguity" [11, p.19]. Further research is warranted to better understand how interprofessional competencies are strengthened while working and learning in austere settings [12] and which learning models are appropriate.

John Biggs [13] developed the 3P model of learning and teaching, further expanded upon by Della Freeth and Scott Reeves, to analyze learning opportunities designed to promote collaborative working [14]. In the 3P model, the three factors that impact IPE are the presage, the process, and the product. The presage factors include the context for learning and teaching, and characteristics of learners, teachers, and program developers. Process factors describe approaches to learning and teaching including the facilitation process, learner choice and participation in curriculum design, customization and authenticity of the learning experience, and reflection and informal learning [14,15]. The intended IPE products "include discipline-specific knowledge, attitudes and behaviours, impact on service delivery and patient/client outcomes" [14, p. 53].

The 3P model appears to be an excellent framework to analyze the acquisition of interprofessional competencies in austere medicine settings where IPE is not part of the formal curriculum. Applying the 3P model, we studied the acquisition of interprofessional competencies as the intervention product in the context of austere presage factors and authentic process factors. The educational intervention we selected for this study was WildER Med, an annual wilderness medicine-learning event [16]. Our research examines the following question: can a wilderness medicine educational event, where interprofessional education is not part of the formal curriculum, lead to improved interprofessional competencies? 
3

Hidden Curriculum in Wilderness-Based Education

Reade, Maar, Cardinal, Boesch, Lacarte, Rollins, \& Jeeves
Journal of Research in Interprofessional Practice and Education

Vol. 6.2

2016

\section{Method}

Prior to the implementation of any research activities, this project received approval from the Laurentian University Ethics Review Board (file number 2012-04-14).

\section{Design}

The design of the study involved four stages (see Figure 1):

- Developmental research included a focus group with wilderness medicine educators to create appropriate audio diary questions and to select an interprofessional education assessment instrument.

- Recruitment of registered WildER Med participants.

- Completion of interprofessional education assessment instruments and audio diaries by study participants at WildER Med (autumn 2012 and 2013).

- Data analysis and integration of quantitative and qualitative data.

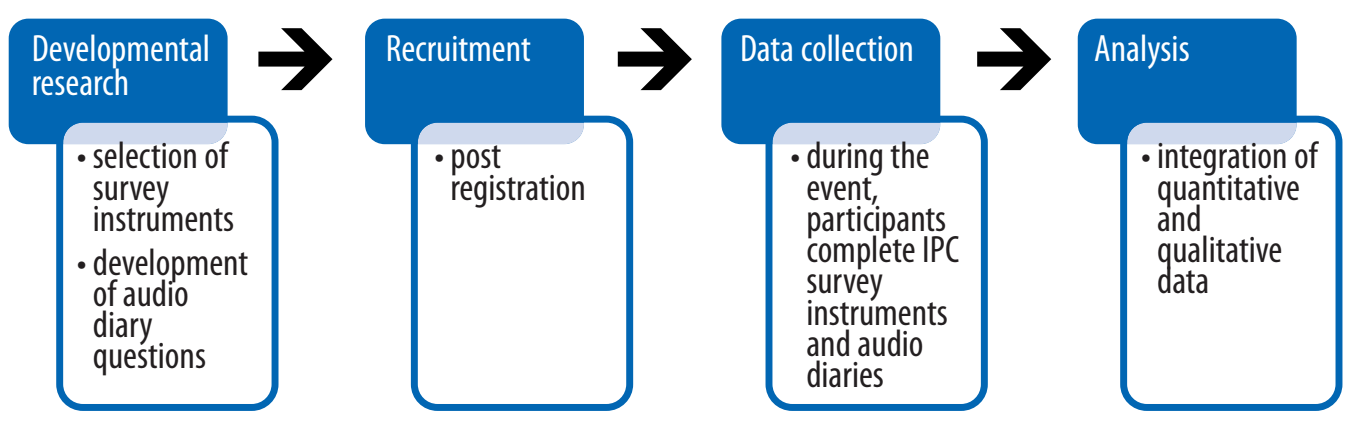

Figure 1: Mixed-method study design

We applied a mixed-methods design as described by John Creswell, Ann Klassen, Vicki Plano Clark, and Katherine Clegg Smith [17]. From the quantitative perspective we assessed if participants' interprofessional competencies changed over the course of their attendance at WildER Med using a validated interprofessional education assessment instrument, the Interprofessional Collaborative Competencies Attainment Survey (ICCAS). We embedded a qualitative audio diary research method to study how the participants experienced interprofessionalism during the day of field exercises. The aim of the mixed-methods research was 1) to determine if there were measurable changes in interprofessional competencies (collaboration, communication, roles and responsibilities, patient-centred care, conflict management, and team functioning) among participants in the event and 2) to analyze audio diary stories to understand how and why participants' IPC changed or not. The data was collected simultaneously during the educational event. The point of interface between qualitative and quantitative methods was during data interpretation.

\section{Recruitment of research participants}

All who registered for the 2012 and 2013 events were invited to participate in the research, via email, with a detailed letter of invitation. Participants in the research 
4

Hidden Curriculum in Wilderness-Based Education

Reade, Maar, Cardinal, Boesch, Lacarte, Rollins, \& Jeeves

Journal of Research in Interprofessional Practice and Education

Vol. 6.2

2016 were from diverse backgrounds including medical, allied healthcare professionals and outdoor leadership. Participation in the research was strictly voluntary.

\section{Setting: The WildER Med event}

The events consisted of three days of experiential wilderness-themed training in an outdoor setting in Northern Ontario. Instructional strategies included didactic sessions, workshops, and field exercises. The formal curriculum objectives included the acquisition and application of survival, navigational, and medical skills appropriate for use in austere settings. Participants worked in interprofessional teams doing common task work that included patient care, survival skills, and navigational components. The third day consisted of field exercises where teams navigated between simulated patient scenarios situated in a wilderness setting. Local actors were used as patients, and the actors also provided formative feedback to the participants after each of the scenarios. Guiding principles of the project included a focus for learners on shared problem solving, a structure "in which no discipline or group has a hierarchical advantage," [18, p. 501] and work with an engaged interprofessional faculty.

\section{Quantitative data collection}

Colla MacDonald, Douglas Archibald, David Trumpower, Lynn Casimiro, Betty Cragg, and Wilma Jelley [19] have developed and validated interprofessional educational assessment instruments designed to assess IPE. From their toolkit, we chose to use both the Learner Contract and the ICCAS. The Learner Contract and the exemplar were provided to participants at the beginning of the weekend as a means to engage the participants in IPE learning and as a self-reflection tool [20]. The ICCAS measures the competencies of interprofessional care using a retrospective pretest/post-test design consisting of 20 questions answered on a seven-point Likert scale [20]. Previous research shows that the psychometric scales of the ICCAS are statistically highly reliable with strong internal consistency when applied to measuring competencies [21]. The retrospective design of the ICCAS enables the participants to reflect upon their competencies prior to and following an educational intervention, thus counteracting response-shift bias [22,23].

The WildER Med participants were requested to complete the ICCAS tool [19] immediately after the scenarios ended. Participants scored their perceived current level of competency and the perceived level of competency prior to the conference, based on the National Interprofessional Competency Framework [24]: 1) communication, 2) patient/client/family/community-centred care, 3) role clarification, 4) team functioning, 5) collaborative leadership, and 6) conflict resolution.

\section{Qualitative data collection}

The participant audio diary guide (see Table 1) was designed during a group discussion with experienced WildER Med facilitators and both research and educational consultants, prior to the 2012 event. The objective was to guide exploration of the wilderness scenarios in relation to the enactment of interprofessional competencies. Participants were asked to complete audio diary entries after each of the five wilder- 
5

Hidden Curriculum in Wilderness-Based Education

Reade, Maar, Cardinal, Boesch, Lacarte, Rollins, \& Jeeves
Journal of Research in Interprofessional Practice and Education

Vol. 6.2

2016 ness scenarios as they navigated to new scenarios. The choice of the mobile audio diaries as a qualitative tool for this study was driven by the desire for both immediacy and contextual relevancy while providing opportunities for self-evaluation and reflection [25].

\section{Table 1: Questions to guide audio diary entry}

\begin{tabular}{|c|l|}
\hline 1. & $\begin{array}{l}\text { Did the team members communicate with each other and the patient and family/friend in a participatory, } \\
\text { collaborative, and coordinated way (interprofessional collaboration) and share decisions? }\end{array}$ \\
\hline 2. & What went well in supporting that collaboration (personally or for the team as a whole)? \\
\hline 3. & What did not go well in that communication/collaboration (personally or for the team as a whole)? \\
\hline 4. & What could have improved communication/collaboration (personally or for the team as a whole)? \\
\hline 5. & How did the live scenario impact on the learning? \\
\hline 6. & What impact did the non-clinical outdoor environment have on your learning? \\
\hline
\end{tabular}

\section{Quantitative data analysis}

Survey data was analyzed using the sign test. The sign test is a non-parametric procedure for comparing two paired samples that makes no assumptions about the normality of distribution or homogeneity of variance [26]. Non-parametric tests have been strongly recommended as more appropriate for analyses involving Likert scales [26,27]. For non-parametric tests, $n>20$ is the recommended sample size, with an absolute minimum of $n>10$ per group [26]. The sample size of this study $(n=28)$ meets these minimum requirements. The statistical analyses were performed using the Statistical Package for the Social Sciences (SPSS) Version 20 (IBM SPSS, Armonk, NY). A measure of effect size was calculated using the formula: $E S=(|z|) / \sqrt{ } n[26]$.

\section{Qualitative data analysis}

The audio diaries were transcribed verbatim and were then thematically coded based on the categories of the National Interprofessional Competency Framework (the same competencies used in the survey research) [24] using NVivo9 Qualitative Research Software. Coding was therefore primarily deductive. The coding was then reviewed and verified by four members of the research team. Any discrepancies were discussed and resolved during two research meetings.

\section{Integration of qualitative and quantitative data analysis}

In this study design, qualitative and quantitative data were collected concurrently, analyzed separately, and then the data sets were integrated to examine the interaction between quantitative and qualitative findings [28]. The survey data was used to demonstrate the change in six interprofessional competencies. The qualitative data was used to triangulate these survey results and to investigate how participants experienced these competency areas during their work on the scenarios. 
6

Hidden Curriculum in Wilderness-Based Education

Reade, Maar, Cardinal, Boesch, Lacarte, Rollins, \& Jeeves
Journal of Research in Interprofessional Practice and Education

Vol. 6.2

2016

\section{Results}

\section{Description of participants}

The participants in the research included ten teams consisting of three to four members each during both conference events, with at least one individual with a medical background, one with an outdoor enthusiast background, and one allied health professional. A total of 34 participants elected to participate in the research component of the conference: 9 men, 15 women, and 10 who did not indicate their gender.

\section{ICCAS competency scores}

While 34 attendees participated in the survey, six surveys were excluded due to incompleteness $(n=28)$. A missing response to an item resulted in excluding the participant's responses for the entire competency theme. A description of responses for each interprofessional competency for the pre-training and post-training survey items is presented in Table 2.

\section{Table 2: Descriptive statistics for each interprofessional competency by pre-training and post-training scores}

\begin{tabular}{|c|c|c|c|c|c|c|c|c|c|c|c|c|c|c|}
\hline & \multicolumn{2}{|c|}{ Communication } & Collaboration & \multicolumn{2}{c|}{$\begin{array}{c}\text { Roles \& } \\
\text { responsibilities }\end{array}$} & \multicolumn{2}{c|}{$\begin{array}{c}\text { Collaborative } \\
\text { approach }\end{array}$} & \multicolumn{2}{c|}{$\begin{array}{c}\text { Conflict } \\
\text { management }\end{array}$} & \multicolumn{2}{|c|}{$\begin{array}{c}\text { Team } \\
\text { functioning }\end{array}$} & \multicolumn{2}{|c|}{$\begin{array}{c}\text { Total } \\
\text { responses }\end{array}$} \\
\hline$n$ & \multicolumn{2}{|c|}{28} & \multicolumn{2}{|c|}{27} & \multicolumn{2}{|c|}{26} & \multicolumn{2}{|c|}{23} & \multicolumn{2}{|c|}{26} & \multicolumn{2}{|c|}{28} \\
\hline & Pre & Post & Pre & Post & Pre & Post & Pre & Post & Pre & Post & Pre & Post & Pre & Post \\
\hline Mdn & 5.80 & 6.20 & 5.67 & 6.33 & 5.50 & 6.25 & 6.00 & 6.33 & 5.67 & 6.50 & 6.00 & 6.50 & 5.63 & 6.20 \\
\hline Min. & 1.00 & 1.00 & 1.00 & 1.00 & 1.25 & 1.25 & 1.00 & 5.00 & 1.00 & 1.00 & 3.00 & 2.00 & 1.35 & 1.18 \\
\hline Max. & 6.80 & 7.00 & 7.00 & 7.00 & 7.00 & 7.00 & 7.00 & 7.00 & 7.00 & 7.00 & 7.00 & 7.00 & 6.95 & 7.00 \\
\hline Range & 5.80 & 6.00 & 6.00 & 6.00 & 5.75 & 5.75 & 6.00 & 2.00 & 6.00 & 6.00 & 4.00 & 5.00 & 5.59 & 5.82 \\
\hline
\end{tabular}

The overall results indicate that there was a small increase in the value of the median in participants' IPE competency scores after completing the WildER Med event. In comparing the before and after scores, there was a statistically significant median increase of 0.68 after participation in the training $(M d n=6.20)$ compared to how participants rated their knowledge and skills before participating in the training $(M d n=5.63)$. The sign test was used to verify the influence the event had on the interprofessional education of participants. The sign test determines how many participants scored themselves higher, lower, or the same after the training compared to how they scored themselves prior to the training (see Table 3). The findings showed there was a significant difference overall between the pre-training scores and the post-training scores in favour of the post-training scores $(z=4.23, p<0.001, E S=0.80)$. Twentyfive participants' post-training scores were slightly higher than the pre-training scores, suggesting an improvement in interprofessional competencies, while only one participant's post-training score did not change from his or her original pre-training score. Two participants had "negative differences," which implies that the event may have had a deleterious influence on their IPE competencies. According to the index guidelines for interpreting the effect size, 0.80 is considered to be a large effect [29]. 
JRIPE

7

Hidden Curriculum in Wilderness-Based Education

Reade, Maar, Cardinal, Boesch, Lacarte, Rollins, \& Jeeves
Journal of Research in Interprofessional Practice and Education

Vol. 6.2

2016
Journal of Research in Interprofessional Practice and Education

Table 3: Results of the sign test comparing differences in post-training scores to pre-training scores

\begin{tabular}{|c|c|c|c|c|c|c|}
\hline Rank & $N$ & $Z$ & SE & $p$-Value & MD & ES \\
\hline \multicolumn{7}{|c|}{ Communication, $n=28$} \\
\hline Positive & 23 & 4.29 & 2.45 & 0.001 & 0.60 & 0.81 \\
\hline Negative & 1 & & & & & \\
\hline Tie & 4 & & & & & \\
\hline \multicolumn{7}{|c|}{ Collaboration, $n=27$} \\
\hline Positive & 21 & 4.36 & 2.29 & 0.001 & 0.67 & 0.84 \\
\hline Negative & 0 & & & & & \\
\hline Tie & 6 & & & & & \\
\hline \multicolumn{7}{|c|}{ Roles and Responsibilities, $n=26$} \\
\hline Positive & 21 & 4.36 & 2.29 & 0.001 & 0.75 & 0.85 \\
\hline Negative & 0 & & & & & \\
\hline Tie & 5 & & & & & \\
\hline \multicolumn{7}{|c|}{ Collaborative Patient-Family Centred Approach, $n=23$} \\
\hline Positive & 16 & 3.40 & 2.06 & 0.001 & 0.67 & 0.71 \\
\hline Negative & 1 & & & & & \\
\hline Tie & 6 & & & & & \\
\hline \multicolumn{7}{|c|}{ Conflict Management/Resolution, $n=26$} \\
\hline Positive & 20 & 3.93 & 2.30 & 0.001 & 0.67 & 0.77 \\
\hline Negative & 1 & & & & & \\
\hline Tie & 5 & & & & & \\
\hline \multicolumn{7}{|c|}{ Team Functioning, $n=25$} \\
\hline Positive & 18 & 3.35 & 2.34 & 0.001 & 1.00 & 0.67 \\
\hline Negative & 2 & & & & & \\
\hline Tie & 5 & & & & & \\
\hline \multicolumn{7}{|c|}{ Total ICCAS Scores, $n=28$} \\
\hline Positive & 25 & 4.23 & 2.60 & 0.001 & 0.68 & 0.80 \\
\hline Negative & 2 & & & & & \\
\hline Tie & 1 & & & & & \\
\hline
\end{tabular}

Notes: $N=$ the number of positive differences, negative differences, and ties; $Z=$ standardized test statistic; $S E=$ standard error; $p$-value $=$ exact significance (2-sided test); $M D=$ median difference; $E S=$ effect size

The ICP communication theme $(n=28)$ showed an improvement in 23 post-training scores, with only one decrease in score and four tied scores, with a significant increase in the median of differences of $0.60, z=4.29, p<0.001, E S=0.81$. The scores on the collaboration theme $(n=27)$ improved for 21 participants, and six participants rated themselves as having no improvement in collaboration $(M D=0.67, z=4.29$, $p<0.001, E S=0.84)$. The roles and responsibilities theme $(n=26)$ showed improvement for 21 participants' scores and five scores remained unchanged $(M D=0.75$, $z=4.36, p<0.001, E S=0.85)$. For the theme of a collaborative patient/family-centred approach $(n=23), 16$ participants rated themselves higher after the training, six par- 
Hidden Curriculum in Wilderness-Based Education

Reade, Maar, Cardinal, Boesch, Lacarte, Rollins, \& Jeeves

Journal of Research in Interprofessional Practice and Education

Vol. 6.2

2016

\section{Journal of Research in Interprofessional Practice and Education}

ticipants rated themselves the same, and one participant reported a lower rating $(M D=0.67, z=3.40, p<0.001, E S=0.71)$. For the conflict management/resolution theme $(n=26), 20$ participants rated themselves higher, five participants reported no difference, and one participant rated himself or herself lower after completing the training $(M D=0.67, z=3.93, p<0.001, E S=0.77)$. The team functioning theme $(n=25)$ saw improvement in 18 participants' scores, with five participants reporting no difference in scores, and one participant reporting a lowered score. The team functioning theme saw the largest increase in the median with differences of $1.00, z=3.35$, $p<0.001, E S=0.67$.

\section{Qualitative analysis of audio diaries}

Audio diary entries indicate that the vividly portrayed scenarios stimulated several areas of reflection about each of the interprofessional competencies. We present the discussion around the ICP themes of communication, patient-centred care, role clarification, team functioning, collaborative leadership, and conflict resolution. The first two are considered to be the domains that support the others [24]. Participant codes were generated by assigning a number to each participant (P1, P2, P3, etc.) followed by a letter representing the team they were assigned to (Team A, B, C, etc.).

\section{Communication}

Participants identified examples of strong communication, such as asking for help when needed, and communicating roles (especially leadership) ahead of time so people knew who to go to for questions/clarification.

We started off a little slow in the communication part ... but what was great was that after we left each scenario we realized that we needed to have a leader set in place before we reached the next scenario and communicate to them exactly what we were thinking and what we were doing. Once we did that we worked rather well as a team and it only helped out the victims because of that. (P14-H)

Participants also recognized strategies that could improve communication, such as avoiding assumptions, active listening, physically separating patients where appropriate, and being verbal with actions.

In the beginning ... we did communicate but it was rather difficult. We weren't actually articulating what we were doing ... we were doing our ABC's and different things but ... people weren't really aware of what we were up to. (P16-I)

\section{Patient/family-centred care}

Participants identified examples of involving patients throughout the treatment process: asking questions, seeking input, and collaborating with patients.

Members of my team requested that my patient communicate with their patient (who) was stressed out about the situation with her hus- 
Hidden Curriculum in Wilderness-Based Education

Reade, Maar, Cardinal, Boesch, Lacarte, Rollins, \& Jeeves

Journal of Research in Interprofessional Practice and Education

\section{Journal of Research in Interprofessional Practice and Education}

band so they requested confirmation that he was doing alright. We were able to connect the two patients without actually having to physically interfere with their care. (P2-C)

The team members communicated well with each other and the patient, to find out what was wrong with them and we all shared our decisions and what we thought was appropriate. (P19-G)

The advantages of having actors rather than mannequins is that the scenarios included the patient-centred approach as well as adding complexity to the simulated learning experience.

I think the live scenarios were really good for learning because it is much different than, say, working on a mannequin or something like that, and you could see how the actors had different personalities or different ... traits that made them easier or more difficult to work with and kind of threw you for a loop sometimes when you maybe didn't expect them to respond that way or things didn't go as planned. (P24-I)

\section{Role clarification}

Teams were encouraged to rotate the leadership roles for each scenario as well as for navigation. However, they continued to operate within their own professional roles. Comments regarding role clarity particularly addressed clarity of leadership and of the distribution of tasks rather than regarding their professional backgrounds.

I think the only thing that we should have changed on this station was more clearly identifying the roles because there was only one patient, and there was one issue we kind of all zoned in on that, and I think maybe we could have done a better job at you know, designating one person as the person that's going to go get help or go um, figure out transportation for instance cause we all kind of were focusing on the same thing, which was helpful because we were able to ... at least for a little bit of time, stabilize the patient, but I think it would have been good to maybe designate the roles a bit more clearly from the get-go ... so we have a little bit less redundancy. (P6-A)

Participants reflected on the importance of having clearly defined roles, the ability to be adaptable when roles suddenly change, and the benefits of the equal distribution of tasks.

What went well is that we were adaptable and could make up for the changes that were happening. (P7-D)

Our first scenario had three ... casualties and we were flustered in the beginning but we started to designate roles ... two of us addressed two of the unconscious casualties and then the other addressed the conscious person. (P8-E) 
Hidden Curriculum in Wilderness-Based Education

Reade, Maar, Cardinal, Boesch, Lacarte, Rollins, \& Jeeves
Journal of Research in Interprofessional Practice and Education
Journal of Research in Interprofessional Practice and Education

Participants identified the conflicting motivations of wanting to perform well, while recognizing that the greatest learning opportunities could occur from assuming roles of lesser expertise.

There's a tendency to want to do the skill that you're good at. I think we could also improve in terms of using this conference to its fullest by doing the skills that we're less good at and allowing others to do those skills, um, and to take a little bit more time. Perhaps I could have had a little bit more to do with building the fire, and less leaving it (for) the people who are more experienced ... (P15-F)

\section{Team functioning}

Participants identified successful strategies for team functioning such as mutual trust and respect, a willingness to learn from others with different backgrounds, supportive approaches, and positive team demeanor.

I felt that each team member was supportive of each other and were [sic] respectful of each other and open to hearing each person's opinion. So, I feel that other people also felt quite comfortable sharing their opinions so that we could discuss as a team all the decisions that we had to make. (P22-I)

Challenges included communication, personality conflicts, not identifying the need to reassess an evolving situation, and optimally matching team strengths with tasks.

I didn't really know what was going on with their patient so maybe a little bit more communication would have been helpful when we were trying to initially triage and figure out who should take who ... and whether any extra help was needed. (P6-A)

\section{Collaborative leadership}

Participants identified the use of each other's strengths and skills in a respectful fashion as a route to strong collaboration. Other factors included clear active communication, assigning roles in advance, and sharing skills and knowledge.

I think when we noticed someone was having a difficult [time] with something we took the time to explain it so that they understood and made sure that no one was getting down on themselves. (P16-I)

Good communication appeared inseparable from the ability to collaborate.

I think just constant communication and not assuming that anyone knows what you're doing unless you're saying it out loud so saying what you're doing when you're doing it, and then making sure that the person you're saying it to, acknowledges that that task's been done. (P6-A)

Not all participants were comfortable in taking a leadership role, and under these circumstances other team members adapted to fill that void. 
Hidden Curriculum in Wilderness-Based Education

Reade, Maar, Cardinal, Boesch, Lacarte, Rollins, \& Jeeves

Journal of Research in Interprofessional Practice and Education

Vol. 6.2

2016

\section{Journal of Research in Interprofessional Practice and Education}

Somebody was supposed to take the lead and eventually somebody just had to go, take it over, which is not a bad thing. We had good communication after that, once the leader ... took charge. (P11-C)

\section{Conflict management/resolution}

Areas of conflict that were identified included control issues among team members, challenges that arose during navigation between scenarios, personality clashes among team members, and opposing views of treatment options among team members with different backgrounds. The need for conflict resolution was often identified within the context of role clarity or overlapping roles.

It (was) difficult because what they're used to [doing] in the nursing [situations], I'm more used to in the bush ... it just led to some arguments. (P23-F)

Some participants chose conflict avoidance in an effort to present a unified team appearance to the patient. Conflict avoidance has been recognized as a means of sparing others emotional distress, but can occur at the expense of long-term team functioning [30].

Sometimes decisions were made at the scene that were not necessarily agreed with by the other members but in order not to argue in front of the patient, we let him continue taking the lead. (P7-D)

Several participants identified successful strategies for conflict resolution involving patience, humour, and persistence. Self-awareness, including the recognition of emotional triggers, was identified as valuable.

I learned that you've just got to be patient and teach people along the way to help [them] improve skills and communication. One of my members is really pushing the levels of my patience [chuckles], but this is a good exercise and a good learning experience. (P7-D)

Participants identified the need for communication and mediation skills, respect, and active listening in order to resolve conflicts.

\section{Discussion}

We use the 3P (presage, process, and product) framework to guide the conversation of the integration of our quantitative and qualitative data. Based on our findings we applied the 3P framework to elaborate the factors within this wilderness event that may level traditional hierarchical and knowledge relationships between participants and help to foster successful IPE/ICP initiatives (see Figure 2).

In the presage, the event took place outdoors in Northern Ontario, with unpredictable weather and challenging terrain. Participants learned wilderness medicine, outdoor survival, and navigational skills within large groups and as small interprofessional teams. The teachers and program developers were from diverse interprofessional backgrounds. Learners varied from students to advanced practitioners with 
12

Hidden Curriculum in Wilderness-Based Education

Reade, Maar, Cardinal, Boesch, Lacarte, Rollins, \& Jeeves
Journal of Research in Interprofessional Practice and Education

Vol. 6.2

2016

\section{- Context: outdoor activity, unpredictable weather \& challenging terrrain, formal curriculum of wilderness medicine, and survival skills, small interprofessional teams \\ - Teacher Programme Developer Characteristics: diverse interprofessional backgrounds, enthusiasm, conceptions of collaboration \\ - Learner Characteristics: diverse interprofessional backgrounds, expectation of experiential wilderness themed training, pre- and post-qualification}

\section{Presage}

\section{Process}

- Approaches to Teaching and

Learning: IPE within hidden curriculum, optional experience, didactic, mini-workshop, and field exercises, shared leadership opportunities, multiday event with informal interaction, authenticity,

facilitator formative feedback, mobile audio diaries

\section{Figure 2: Examining wilderness education using the 3P model (adapted from Freeth and Reeves [14])}

backgrounds such as medicine, nursing, and outdoor leadership. A sense of equality, or an equal playing field in the learning environment appears to be a critical aspect to enable interprofessional learning [18,31]. At this event, time spent together as a team, the opportunity to build friendships, the willingness to trust and help each other, the common goals, the common training received to respond to the scenarios, and the use of simulated patients are factors that help to level the playing field within the educational experience.

The process factors consider approaches to learning and teaching. Interprofessional teaching was key to both informal and hidden aspects of the curriculum, but was not addressed within the formal curriculum. This elective event lasted three days giving many opportunities for informal interaction, including at mealtimes, evenings, and during shared camping experiences. Participants wore outdoor clothing that did not reinforce medical hierarchies. Instructional strategies included didactic sessions, mini workshops, field exercises, and simulated wilderness-based patient scenarios. During the teamwork, members were expected to stay within their roles, but to share leadership opportunities. Facilitators provided formative feedback to teams regarding their wilderness medicine skills and decision-making, while simulated patients provided authentic patient and family-centred formative feedback after the scenarios. This level of authenticity is "a characteristic that arises when the development and delivery process are customized to the particular learning group and their professional practice" and is increasingly recognized as part of good IPE practice with an emphasis on the use of "simulated patients and learning in practice or simulated practice settings" $[15,748]$. Specific strategies to level traditional hierarchical and knowledge relationships between participants are part of both the presage and the process at WildER Med. 
Hidden Curriculum in Wilderness-Based Education

Reade, Maar, Cardinal, Boesch, Lacarte, Rollins, \& Jeeves

Journal of Research in Interprofessional Practice and Education

Vol. 6.2

2016
The product of the (hidden and informal) IPE was the focus of our mixed-methods research. The quantitative data suggests that there was a statistically significant improvement in each of the competencies we examined using the ICCAS tool. The "large" effect size implies that the workshop was found to be an effective intervention for advancing interprofessional education and collaboration. The qualitative research findings shed greater light on the reflections, experiences, and challenges of the participants.

Communication styles that allowed for team negotiation, consultation, and discussion created an environment where participants could be both responsive and become responsible to each other. The feedback provided by simulated patients to the teams supported the concept of shared patient-centred decision-making and patient-centred care. Participants were able to reflect upon how communication could improve the overall patient experience and health outcomes. While clearly defined roles within the teams were recognized as a benefit, participants who were able to rotate leadership roles and tasks also identified this as a useful learning opportunity. Being adaptable to changing circumstances, particularly a willingness to change roles as required, was identified as strength of the team. Participants identified that the integration of respect, trust, cooperation, collaboration, and a commitment to communication could enable a supportive and effective environment contributing to team function. While many participants took the opportunity to assume a leadership role, a supportive, shared, decision-making style seemed to be common. In these short-lived teams, participants appeared to adapt to situations where individuals were reluctant to assume that leadership role. The acknowledgement and recognition of conflict is an essential part of constructive conflict resolution. Collaborative teams develop strategies for conflict resolution and consensus within a safe environment leading to the establishment of respectful, effective, healthy relationships. In some situations, participants used conflict avoidance but that technique may hinder the development or maturation of teams that last for a longer time.

Comments were often reflective of the Canadian Interprofessional Health Collaborative position that communication and patient-centred care support the other IPC domains [24]. Overall, our mixed-methods research suggests that the training provided positive benefits toward the improvement of interprofessional collaboration as perceived by the participants. Our research suggests that working within situations of limited resources may encourage participants to examine the resources within their teams, since there is limited opportunity to improve the team's approach through either outside intervention or increased technology.

Practitioners at all stages of their careers are now expected to understand and communicate about the function or dysfunction of their teams. "This discourse of talk and writing about teams does not necessitate a formal engagement with the theory of teams, but it does invoke reflective capacity in thinking about working in team settings that may be elaborated and discussed with colleagues" [11, p. 19]. Audio diaries may help to narrow that gap between the discourse of teamwork and those who do teamwork, while providing opportunities for ongoing self-evaluation and reflection. 
Hidden Curriculum in Wilderness-Based Education

Reade, Maar, Cardinal, Boesch, Lacarte, Rollins, \& Jeeves

Journal of Research in Interprofessional Practice and Education

Vol. 6.2

2016
Audio diaries created the opportunity for reflection and organizational and communication adjustments between scenarios. Mobile audio diaries may be particularly useful during IPE simulation such as disaster medicine in order to capture "spontaneous, moment-by-moment accounts of experience" [32, p. 22], which can reflect the priorities of participants and offer perspectives into team function that are not captured by solely retrospective interviews. Longitudinal audio diaries could be examined as a tool for IPE workplace learning opportunities. The 3P model could be utilized to evaluate other educational opportunities where interprofessional education is within the informal and hidden curriculum using content topics such as addictions medicine or palliative care.

Opportunities exist for further research into the intersection of IPE and austere medicine. This includes the examination of how best to incorporate interprofessional education into disaster medicine curricula [12], and how to develop and support ICP for those teams that have intense but infrequent working relationships [8].

Conflict resolution was a recurring challenge for participants as reflected in the audio diaries. This parallels the findings of other researchers $[7,33]$ who have identified conflict management as a particular topic requiring targeted skill building, and that may not be as readily acquired in IPE interventions [33]. Continuing education events where IPE exists within the hidden curriculum may benefit from addressing conflict resolution skills overtly. Understanding barriers to conflict resolution is an area of particular interest in future curriculum design for interprofessional education [30].

While mixing expert and non-expert roles within an IPE activity may foster greater appreciation of the roles of others on the team, it would not be appropriate during workplace IPE learning. Some areas of austere medicine in particular rely upon hierarchical systems such as incident command systems and so attempts to improve teamwork through the flattening of hierarchy may not be a viable option in these areas [8].

Elise Paradis and Cynthia Whitehead [34] have called for further research into power and conflict within interprofessional education. Simulation does provide learners with the possibility to explore these power relationships, and could be examined further whether IPE is overt, informal, or hidden.

\section{Conclusions}

IPE and ICP are thought to be important routes to improve patient safety and to build resilient healthcare teams. Part of that pathway may include the principles of having learners working on problems where no discipline has a hierarchical advantage and using engaged interprofessional faculty [18].

As health providers face a multitude of choices for professional development, layering IPE onto other educational opportunities may be both efficient and capture a wider audience. Educational opportunities where IPE may be currently hidden or informal should thus be further examined. Austere medicine education, including wilderness medicine, represents an opportunity for problem-based learning, for simulation, and for curricular design that can incorporate an equal playing field within the learning environment while integrating IPE. 
15

Hidden Curriculum in Wilderness-Based Education

Reade, Maar, Cardinal, Boesch, Lacarte, Rollins, \& Jeeves
Journal of Research in Interprofessional Practice and Education

Vol. 6.2

2016

\section{Acknowledgements}

We thank the Manitoulin Wilderness Medical Educators for their diligent contribution to making this event a success and the Debajehmujig Storytellers for providing highly skilled actors that played the role of the patients during the simulated scenarios. We also acknowledge the funding support for this project provided by the Northern Ontario Academic Medicine Association through the AFP Innovation Fund and from the Manitoulin Island Clinical Teachers' Association.

\section{Abbreviations}

ICCAS: The Interprofessional Collaborative Competencies Attainment Survey

ICP: Interprofessional Collaborative Practice

IPE: Interprofessional Education

\section{References}

1. O'Daniel, M., \& Rosenstein, A.H. (2008, April). Professional communication and team collaboration. In R.G. Hughes (Ed.), Patient safety and quality: An evidence-based handbook for nurses, Chapter 33. Rockville, MD: Agency for Healthcare Research and Quality. URL: http://www.ncbi .nlm.nih.gov/books/NBK2637/ [August 3, 2015].

2. CAIPE | Resources > Defining IPE. (n.d.). CAIPE. URL: http://caipe.org.uk/about-us/defining-ipe/ [July 5, 2015].

3. Hafferty, F.W. (1998). Beyond curriculum reform: Confronting medicine's hidden curriculum. Academic Medicine: Journal of the Association of American Medical Colleges, 73(4), 403-407.

4. Bennett, N., Lockyer, J., Mann, K., Batty, H., LaForet, K., Rethans, J-J., \& Silver, I. (2004). Hidden curriculum in continuing medical education. Journal of Continuing Education in the Health Professions, 24(3), 145-152.

5. Framework for Action on Interprofessional Education \& Collaborative Practice URL: http:// WHO _HRH_HPN_10.3_eng.pdf . (2010). URL: http://apps.who.int/iris/bitstream/10665/70185/1/ WHO_HRH_HPN_10.3_eng.pdf [April 4, 2012].

6. Macias, D.J., \& Williams, J. (2013). Austere, remote, and disaster medicine missions: An operational mnemonic can help organize a deployment. Southern Medical Journal, 106(1), 89-93.

7. Willems, A., Waxman, B., Bacon, A. K., Smith, J., \& Kitto, S. (2013). Interprofessional non-technical skills for surgeons in disaster response: A literature review. Journal of Interprofessional Care, 27(5), 380-386.

8. Peller, J., Schwartz, B., \& Kitto, S. (2013). Nonclinical core competencies and effects of interprofessional teamwork in disaster and emergency response training and practice: A pilot study. Disaster Medicine and Public Health Preparedness, 7(4), 395-402.

9. West, C., Veronin, M., Landry, K., Kurz, T., Watzak, B., Quiram, B., \& Graham, L. (2015). Tools to investigate how interprofessional education activities link to competencies. Medical Education Online, 20:28627. http://dx.doi.org/10.3402/meo.v20.28627

10. Atack, L., Parker, K., Rocchi, M., Maher, J., \& Dryden, T. (2009). The impact of an online interprofessional course in disaster management competency and attitude towards interprofessional learning. Journal of Interprofessional Care, 23(6), 586-598.

11. Bleakley, A. (2013). Working in "teams" in an era of "liquid" healthcare: What is the use of theory? Journal of Interprofessional Care, 27(1), 18-26.

12. Barnett-Vanes, A., \& Luis Guinto, R.L. (2013). Disaster curricula in medical and health care education: Adopting an interprofessional approach. Prehospital and Disaster Medicine, 28(6), 644-645.

13. Biggs, J.B. (1993). From theory to practice: A cognitive systems approach. Higher Education Research \& Development, 12(1), 73-85.

14. Freeth, D., \& Reeves, S. (2004). Learning to work together: Using the presage, process, product (3P) model to highlight decisions and possibilities. Journal of Interprofessional Care, 18(1), 43-56.

15. Hammick, M., Freeth, D., Koppel, I., Reeves, S., \& Barr, H. (2007). A best evidence systematic review of interprofessional education: BEME Guide no. 9. Medical Teacher, 29(8), 735-751.

16. WildER Med. (n.d.). WildER Med. URL: http://www.wildermed.org/ [April 3, 2016]. 
Hidden Curriculum in Wilderness-Based Education

Reade, Maar, Cardinal, Boesch, Lacarte, Rollins, \& Jeeves
Journal of Research in Interprofessional Practice and Education

Vol. 6.2

2016
17. Creswell, John W., Klassen, Ann C., Plano Clark, Vicki, \& Clegg Smith, Katherine (2011). Best practices for mixed methods research in the health sciences. Bethesda, MD: Office of Behavioral and Social Sciences Research (OBSSR).

18. Ladden, M.D., Bednash, G., Stevens, D.P., \& Moore, G.T. (2006). Educating interprofessional learners for quality, safety and systems improvement. Journal of Interprofessional Care, 20(5), 497-505.

19. MacDonald, C.J., Archibald, D., Trumpower, D., Casimiro, L., Cragg, B., \& Jelley, W. (2010). Designing and operationalizing a toolkit of bilingual interprofessional education assessment instruments. Journal of Research in Interprofessional Practice and Education, 1(3). URL: http:// www.jripe.org/index.php/journal/article/view/36 [September 15, 2012].

20. MacDonald, C.J., Archibald, D., Trumpower, D.L., Casimiro, L., Cragg, B., \& Jelley, W. (n.d.). W(e)Learn IPE instruments. URL: http://ennovativesolution.com/WeLearn/IPE-Instruments .html [September 5, 2012].

21. Archibald, D., Trumpower, D., \& MacDonald, C.J. (2014). Validation of the interprofessional collaborative competency attainment survey (ICCAS). Journal of Interprofessional Care, 28(6), 553-558.

22. Howard, G.S. (1980). Response-shift bias: A problem in evaluating interventions with pre/post selfreports. Evaluation Review, 4(1), 93-106.

23. Tolleson, S.R., Ismail, N.J., Gill, A.C., Dello Stritto, R.A., Hatfield, M.D., Teal, C. R., Nelson, E.A., \& Hatfield, C.L. (2016). Changes in pharmacy students after experiencing interprofessional education activities. Journal of Research in Interprofessional Practice and Education, 6(1). URL: http://www.jripe.org/index.php/journal/article/view/222 [May 9, 2016].

24. Canadian Interprofessional Health Collaborative. (2010). A national interprofessional competency framework. Vancouver, BC: Canadian Interprofessional Health Collaborative. URL: http://www .cihc.ca/files/CIHC_IPCompetencies_Feb1210.pdf [October 14, 2012].

25. Crozier, S.E., \& Cassell, C.M. (2016). Methodological considerations in the use of audio diaries in work psychology: Adding to the qualitative toolkit. Journal of Occupational and Organizational Psychology, 89(2), 396-419.

26. Corder, G.W., \& Foreman, D.I. (2014). Nonparametric statistics: A step-by-step approach (second edition.). Hoboken, NJ: Wiley.

27. Nanna, M.J., \& Sawilowsky, S.S. (1998). Analysis of Likert scale data in disability and medical rehabilitation research. Psychological Methods, 3(1), 55-67.

28. Fetters, M.D., Curry, L.A., \& Creswell, J.W. (2013). Achieving integration in mixed methods designsprinciples and practices. Health Services Research, 48(6pt2), 2134-2156.

29. Cohen, J. (1977). Statistical power analysis for the behavioral sciences (revised edition). New York, NY: Academic Press.

30. Brown, J., Lewis, L., Ellis, K., Stewart, M., Freeman, T.R., \& Kasperski, M.J. (2011). Conflict on interprofessional primary health care teams - can it be resolved? Journal of Interprofessional Care, 25(1), 4-10.

31. Clark, P.G. (2011). The devil is in the details: The seven deadly sins of organizing and continuing interprofessional education in the US. Journal of Interprofessional Care, 25(5), 321-327.

32. Williamson, I., Leeming, D., Lyttle, S., \& Johnson, S. (2015). Evaluating the audio-diary method in qualitative research. Qualitative Research Journal, 15(1), 20-34.

33. Paterson, M.L., Medves, J., Dalgarno, N., O’Riordan, A., \& Grigg, R. (2013). The timely open communication for patient safety project. Journal of Research in Interprofessional Practice and Education, 3(1). URL: http://www.jripe.org/index.php/journal/article/view/65 [February 1, 2016].

34. Paradis, E., \& Whitehead, C. R. (2015). Louder than words: Power and conflict in interprofessional education articles, 1954-2013. Medical Education, 49(4), 399-407. 